Revista Destaques Acadêmicos, Lajeado, v. 12, n. 1, 2020. ISSN 2176-3070

DOI: http://dx.doi.org/10.22410/issn.2176-3070.v12i1a2020.2500

http://www.univates.br/revistas

\title{
IMPLEMENTAÇÃO DO BEYOND BUDGETING: DESAFIOS, VANTAGENS E CRÍTICAS
}

\author{
Rita de Cássia da Silva Vilanova ${ }^{1}$, Alexandre André Feil ${ }^{2}$
}

Resumo: O Beyond Budgeting estabelece um modelo de gestão alternativo, flexível, descentralizado e participativo. Neste sentido, este estudo objetiva analisar os desafios, vantagens e críticas na implementação do Beyond Budgeting. A metodologia utilizada é qualitativa, descritiva e o procedimento técnico estratifica-se como estudo de caso, sendo que a obtenção dos dados ocorreu mediante entrevista semiestruturada e pesquisa documental primária. As principais dificuldades na implementação do Beyond Budgeting na Industria A relacionam-se a centralização da gestão, a falta de uma adequada formalização de controles e procedimentos relacionados a governança corporativa e segregação de funções, e a carência de políticas de planejamento estratégico e operacional. As facilidades encontradas para a adaptação e implementação do orçamento Beyond Budgeting relacionam-se a disponibilidade dos proprietários em aprimorar o modelo tradicional de orçamento, migração para um software de gestão que agilize os processos e disponibilidade de flexibilizar o orçamento tradicional, modificando principalmente a forma de gestão centralizada. Conclui-se que apesar das críticas e desafios na implementação do orçamento Beyond Budgeting os proprietários da Indústria A solidificam sua aceitação como uma ferramenta eficiente e capaz de gerar resultados satisfatórios.

Palavras-chave: Orçamento empresarial, Dificuldades, modelos orçamentários.

\section{INTRODUÇÃO}

O orçamento empresarial é um instrumento essencial de planejamento e controle, estabelece ações de prevenção a serem desempenhadas e os recursos indispensáveis para produzir e auferir a receita projetada (BROMAN; PINTO, 2017). Estes autores ainda salientam que deve ser acompanhado

1 Universidade do Vale do Taquari - Univates. Graduada em Ciências contábeis pela Universidade Univates.

2 Universidade do Vale do Taquari - Univates. Doutor em Qualidade Ambiental pela Universidade Feevale. Universidade do Vale do Taquari - Univates. Docente permanente do Programa de Pós Graduação Stricto Sensu Mestrado em Sistemas Ambientais Sustentáveis. 
constantemente, comparando o orçado com o realizado, de forma que sejam efetuados os ajustes necessários, uma vez que os fatores externos, como cenário econômico e mercadológico, exógenos à empresa, podem influenciar diretamente na execução do orçamento.

$\mathrm{Na}$ definição de um planejamento orçamentário as empresas traçam metas a serem atingidas, com o desejo de programar a organização, mesmo sabendo que o cenário muda e que gasta-se longo tempo renegociando as metas orçamentarias (ROSENBURG, 2008). Porém, em um cenário de constantes mudanças, as empresas devem procurar práticas mais adequadas e flexíveis para substituir a função do orçamento tradicional.

Uma metodologia utilizada para caracterizar esse processo de gestão flexível sem orçamento anual de resultados ou com orçamentos adaptáveis à realidade das empresas, denomina-se Beyond Budgeting, que tem o propósito de adotar práticas de governança de forma descentralizada para otimizar as decisões dos gestores (JERÔNIMO, 2018).

Na literatura, em termos globais, há casos de adoções e implementação do orçamento Beyond Budgeting na Volvo, Borealis, Boots, Toyota, Scania, Ericsson, Unilever Best Foods, Ikea, Tetra Pak, Rhodia, Siemens, entre outros (QUEIRÓS, 2010). No Brasil, as empresas que já estão utilizando o modelo de orçamento tradicional, tais como a Rhodia, Philips, Ericsson, Totvs e Votorantim Celulose e Papel, estão estudando substitui-lo pelo orçamento Beyond Budgeting (PELEIAS et al., 2012).

O orçamento Beyond Budgeting tem como principal benefício um modelo de gestão flexível e descentralizado, o que o diferencia do modelo de orçamento tradicional, que tem alto custo com planos e metas fixas preestabelecidas (JERÔNIMO, 2018). Lopes, Marques e Penha (2018) pesquisaram em publicações nacionais, entre os anos de 2005 e 2017, a utilização do orçamento Beyond Budgeting e encontraram oito artigos, neste sentido, nota-se a escassez de literatura existente sobre a temática.

Neste contexto, este estudo objetiva avaliar os desafios, vantagens e críticas para a análise da viabilidade de uma proposta de implementação do Beyond Budgeting em uma indústria. Este estudo possui relevância tanto para o meio acadêmico como para o profissional, pois o Beyond Budgeting é abordado de forma escassa na literatura e na prática empresarial. A pesquisa contribui para outros estudos, como aprimoramento da análise do orçamento Beyond Budgeting como forma de substituição ao modelo de orçamento tradicional.

\section{REFERENCIAL TEÓRICO}

\section{Conceitos e finalidades do Beyond Budgeting}

O Beyond Budgeting é um conjunto coeso de processos alternados que apoiam objetivos relativos e recompensas, planejamento contínuo, recursos 
exigidos, coordenação dinâmica entre os departamentos na empresa, e uma elaboração detalhada de controles multiníveis (HOPE; FRASER, 2003). O Beyond Budgeting é um método de gestão flexível, descentralizada e participativo que desqualifica os orçamentos como base para a gestão empresarial (PELEIAS et al., 2012).

Fraser e Pflaeging (2007) consentem que o Beyond Budgeting é a base de um novo movimento que está buscando alternativas para criar organizações enxutas e adaptáveis que podem sustentar uma performance competitiva. $\mathrm{O}$ objetivo deste movimento é desenvolver e disseminar a ideia através de um grupo crescente e vibrante.

O Beyond Budgeting tem como objetivo básico um conjunto de princípios direcionados à flexibilização e descentralização da gestão, que deve ser adicionado pelos modelos de gestão das empresas para torná-los mais ajustados ao ambiente empresarial (BARBOSA FILHO; PARISI, 2006). Sendo assim, o Beyond Budgeting identificou como caminho a abdicação do orçamento como instrumento de gestão e, com isso, trazer a eliminação de jogos corporativos e a centralização da gestão.

Hope e Fraser (2003, p. 19) salientam que a abordagem Beyond Budgeting é um "[...] grupo de processos alternativos que apoiam metas e reconhecimentos, um planejamento contínuo, a demanda de recursos, a coordenação dinâmica da empresa e um significativo grupo de controles nos vários níveis". Este orçamento não estabelece um processo anual de negociação que resulte em uma meta fixa, mas exige maior confiança entre os participantes, concentrando-se na relação entre os executivos seniores e a gerência da empresa (FREZATTI, 2005).

\section{Critérios e passos para a implementação do Beyond Budgeting}

O Beyond Budgeting possui 12 princípios os quais estão divididos em dois grupos (BBRT, 2003): I) os seis primeiros abrangem regras de descentralização e liderança; e II) os demais, o processo de gestão e desempenho. O Quadro 1 descreve os 12 princípios com um detalhamento de cada segmento. 


\section{I - Princípios de descentralização e liderança:}

1. Governança: Estabelece uma infraestrutura para transmitir uma proposta que esclareça princípios e valores e não exerce um controle central por meio de regras e procedimentos;

2. Responsabilidade pelo desempenho: Institui que as pessoas se responsabilizem pelos números na busca de resultados competitivos, não apenas com reuniões de objetivos funcionais;

3. Empowerment/Delegação: Concede liberdade às pessoas e capacita-as para agir, não mantém controle ou restrições sobre elas;

4. Estrutura/Organização: Organiza uma rede interdependente de divisões orientadas para o cliente e não uma hierarquia de funções e departamentos;

5. Coordenação: Coordena interações cruzadas dos sistemas da empresa e não ações detalhadas dos orçamentos;

6. Liderança: Desafia e treina os recursos humanos, não somente as comanda e controla.

\section{II - Processo de gestão e desempenho:}

1. Quadro de objetivos: Superar os concorrentes e não os orçamentos;

2. Processo estratégico: Elaborar um processo estratégico contínuo e inclusivo, não um evento anual Top-Down;

3. Gestão antecipada: Utilizar sistemas de previsão para informar a estratégia e não as ações corretivas de curto prazo para manter-se no caminho;

4. Gestão de recursos: Providenciar recursos para as operações a um custo justo, e não determinado a partir do centro e com uma afetação anual;

5. Mensuração e controle: Fornecer informações rápidas e abertas e não vários relatórios pormenorizados de micro gestão;

6. Motivação e recompensas: Realizar com base num nível de desempenho competitivo e não em metas negociadas e fixadas antecipadamente.

Fonte: Adaptado de BBRT (2003).

Na implementação do modelo de orçamento Beyond Budgeting, conforme Pflaeging (2009), além dos princípios base, deve-se respeitar três pré-requisitos: a) Timing: A empresa de forma geral deve atingir um nível de insatisfação que desperte o interesse de mudança; b) Visão: É preciso que haja um cenário de modificação que dissemine a visão entre os colaboradores; e c) Estratégia: Todo planejamento de mudança deve ter uma estratégia na qual exista confiabilidade, principalmente no início das medidas, em função dos riscos e incertezas.

Os critérios na elaboração do Beyond Budgeting relacionam-se aos princípios dos processos flexíveis, e como eles proporcionam alternativas que alteram as atitudes e os comportamentos nas organizações, conforme detalhado no Quadro 2. 
Cenário dos objetivos - Metas de longo prazo, visando melhorias com objetivos fundamentados na maximização do seu desempenho de curto e longo prazo. As metas e os objetivos são baseados em medidas relativas, que serão as bases para o desempenho ser medido e recompensado. A análise do desempenho dos objetivos pode ser por meio de benchmarks externos, pares internos, grupos de ligas ou associações, e o ano anterior comparado com o ano atual.

Motivação e recompensas - A análise de desempenho ocorre por medidas relativas, que identificam as melhorias de desempenho. A ênfase ocorre pelo desempenho das equipes, grupos e empresas e a avaliação não será individual. O objetivo é estimular o compartilhamento, garantindo que toda a organização encaminhe-se para o mesmo rumo.

Planos de ações - O plano de ação deve contemplar o ano fiscal que deve ser o período de tempo base dos relatórios de resultados a serem analisados pelos investidores.

Gestão dos recursos - A responsabilidade de desempenho deve ser transmitida para os gerentes operacionais (descentralização da hierarquia); assim, eles devem ter acesso rápido aos recursos, quando necessitarem.

Coordenação das ações - Na maioria das organizações, o orçamento estipula um acordo financeiro para o ano seguinte, porém em uma organização sem orçamento tradicional, não existe um plano. Dessa forma, os gerentes devem organizar os compromissos, conforme a demanda do mercado.

Controle de desempenho - Intercalar a ênfase das medidas de desempenho, descentralizando os controles; apreciar o que está acontecendo, no entanto, somente intervir quando absolutamente necessário, fornecendo controles que incluem uma governança eficaz e que também gerem subsídios para a tomada de decisão. Os indicadores de desempenho podem relacionar-se a governança eficaz, resultados financeiros rápidos e reais, análise de tendências, Rolling financial forecasts, Key Performance Indicator (KPIs), faixas de desempenhos, entre outros.

Fonte: Adaptado de Hope e Fraser (2003).

Um plano eficiente e ágil de execução do Beyond Budgeting não é realizado da noite para o dia (QUEIRÓS, 2010). A autora ainda enfatiza que o plano de execução mais agressivo, demorou de dois a três anos para concluir o processo de mudança de mentalidade, ainda que tivesse sido rápido na remoção dos contratos fixos de desempenho, pois gerenciar os riscos e incertezas do projeto é uma das chaves do sucesso.

Queirós (2010) destaca que as mudança devem ser gradativas, sendo que os líderes persistem em manter um controle central rígido da mensuração de desempenho com base em estimativas. Salienta ainda que a melhor forma é prosseguir com três fases: a) Primeira fase: Divulgar a visão; b) Segunda fase: Idealizar e implementar o novo sistema; e c) Terceira fase: Implementar a descentralização progressiva. Antes de iniciar estas três etapas deve-se preparar um processo de mudança, alcançando a devida aceitação para as necessidades da primeira etapa, de forma a alcançar o sucesso. 


\section{Estudos precedentes sobre Beyond Budgeting no Brasil}

Os objetivos e resultados de estudos precedentes sobre o Beyond Budgeting, estão apresentados no Quadro 3, observando-se que as pesquisas ainda são recentes no Brasil e tentam esclarecer o que é essa ferramenta e à percepção quanto a sua aplicabilidade e adoção.

Quadro 3 - Principais resultados e conclusões de pesquisas anteriores

\begin{tabular}{|c|c|c|}
\hline $\begin{array}{c}\text { Autor e } \\
\text { Ano }\end{array}$ & Objetivo & Principais Resultados \\
\hline $\begin{array}{l}\text { Soares } \\
\text { e Neves } \\
\text { Júnior } \\
(2003)\end{array}$ & $\begin{array}{l}\text { Estudar o novo modelo de } \\
\text { gestão comparando-o com o } \\
\text { orçamento tradicional. }\end{array}$ & $\begin{array}{l}\text { Viabilidade mediante o aproveitamento } \\
\text { de técnicas e sugestões propostas pelo } \\
\text { Beyond Budgeting e melhorar os pontos } \\
\text { críticos do orçamento. }\end{array}$ \\
\hline $\begin{array}{l}\text { Barbosa } \\
\text { Filho } \\
(2004)\end{array}$ & $\begin{array}{l}\text { Avaliar se uma empresa } \\
\text { brasileira de grande porte } \\
\text { do ramo de alimentos tem } \\
\text { tendência em adotar o novo } \\
\text { modelo. }\end{array}$ & $\begin{array}{l}\text { A empresa apresentou tendência em } \\
\text { adotar os princípios do Beyond Budgeting, } \\
\text { pois se aproxima dos conceitos e } \\
\text { princípios deste novo modelo de gestão. }\end{array}$ \\
\hline $\begin{array}{c}\text { Frezatti } \\
(2005)\end{array}$ & $\begin{array}{l}\text { Analisar a expressão "Beyond } \\
\text { Budgeting" e se ela constitui } \\
\text { uma inovação. }\end{array}$ & $\begin{array}{l}\text { Verifica-se que o foco da gestão na } \\
\text { abordagem Beyond Budgeting está no } \\
\text { gestor, na sua flexibilização. }\end{array}$ \\
\hline $\begin{array}{c}\text { Taranto } \\
(2006)\end{array}$ & $\begin{array}{l}\text { Avaliar se a proposta do } \\
\text { modelo Beyond Budgeting } \\
\text { pode substituir ao } \\
\text { Planejamento Orçamentário } \\
\text { no processo de gestão } \\
\text { empresarial. }\end{array}$ & $\begin{array}{l}\text { Revela que não há abandono do } \\
\text { orçamento como um todo, mas de } \\
\text { sua natureza de fixar metas. Também } \\
\text { confirmou as dificuldades quanto à } \\
\text { obtenção e utilização de benchmarking. }\end{array}$ \\
\hline $\begin{array}{l}\text { Gimenez } \\
\text { et al. } \\
(2009)\end{array}$ & $\begin{array}{l}\text { Realizar uma comparação } \\
\text { entre Gestão Econômica e } \\
\text { o Beyond Budgeting, com o } \\
\text { objetivo de estabelecer suas } \\
\text { principais diferenças. }\end{array}$ & $\begin{array}{l}\text { Os modelos nasceram da mesma } \\
\text { motivação, encontrar novos caminhos } \\
\text { para a gestão, divergindo quanto à } \\
\text { metodologia. Portanto, ambos apoiam-se } \\
\text { no orçamento como instrumento de apoio } \\
\text { a decisão. }\end{array}$ \\
\hline $\begin{array}{c}\text { Queirós } \\
\text { (2010) }\end{array}$ & $\begin{array}{l}\text { Estudar este novo modelo } \\
\text { de gestão, compará-lo com o } \\
\text { orçamento tradicional. }\end{array}$ & $\begin{array}{l}\text { Empresas mais recentes utilizam } \\
\text { significativamente menos os orçamentos } \\
\text { do que as empresas mais antigas. }\end{array}$ \\
\hline $\begin{array}{l}\text { Peleias et } \\
\text { al. (2012) }\end{array}$ & $\begin{array}{l}\text { Analisar as percepções de } \\
\text { um grupo de gestores sobre } \\
\text { o Beyond Budgeting, para } \\
\text { estudar sua aplicabilidade à } \\
\text { organização. }\end{array}$ & $\begin{array}{l}\text { As evidências são suficientes para } \\
\text { motivar a adoção do Beyond Budgeting, ou } \\
\text { seja, agilidade, autonomia e agregação de } \\
\text { valor. }\end{array}$ \\
\hline $\begin{array}{c}\text { Gabriel } \\
(2016)\end{array}$ & $\begin{array}{l}\text { Examinar se o Beyond } \\
\text { Budgeting pode ser um } \\
\text { substituto do orçamento. }\end{array}$ & $\begin{array}{l}\text { Foi possível averiguar que na grande } \\
\text { maioria deles, o ponto inicial são as } \\
\text { críticas ao orçamento tradicional. }\end{array}$ \\
\hline
\end{tabular}




\begin{tabular}{|c|l|l|}
\hline $\begin{array}{c}\text { Autor e } \\
\text { Ano }\end{array}$ & \multicolumn{1}{|c|}{ Objetivo } & \multicolumn{1}{|c|}{ Principais Resultados } \\
\hline $\begin{array}{c}\text { Valente } \\
(2016)\end{array}$ & $\begin{array}{l}\text { Propor a implementação de } \\
\text { um modelo de orçamentação } \\
\text { alternativo. }\end{array}$ & $\begin{array}{l}\text { Eliminar ineficiências encontradas; } \\
\text { permitindo e incentivando a inovação } \\
\text { contínua, tornando-se mais adaptável ao } \\
\text { ambiente que integra. }\end{array}$ \\
\hline $\begin{array}{c}\text { Gama, } \\
\text { Negreiros } \begin{array}{l}\text { Souza } \\
(2018)\end{array}\end{array}$ & $\begin{array}{l}\text { Mostrar os efeitos da } \\
\text { aplicação do Beyond Budgeting } \\
\text { em relação ao Orçamento } \\
\text { Estático, Flexível, Contínuo e } \\
\text { Base Zero. }\end{array}$ & $\begin{array}{l}\text { O Beyond Budgeting traz maior } \\
\text { flexibilidade a gestão financeira, trazendo } \\
\text { mais possibilidades para alçarem o } \\
\text { sucesso, tornando a gestão financeira } \\
\text { tranquila, pois estabelece mecanismos } \\
\text { para mudanças rápidas. }\end{array}$ \\
\hline
\end{tabular}

Fonte: Elaborado pelos autores.

O Beyond Budgeting já está disseminado em alguns países da Europa e América do Norte, atua com base em vários princípios, tendo como principal proposta, a descentralização do poder e da tomada de decisão nas empresas, obtendo resultados positivos na organização, em virtude da simplicidade e agilidade no processo decisório, proporcionando uma melhor adaptabilidade (BARBOSA FILHO, 2004).

Barbosa Filho (2004) também analisa a tendência do modelo Beyond Budgeting e observa que as empresas tem tendências em adotar seus princípios, porém constatou que é necessário quebrar diversos paradigmas para implementar um novo modelo de gestão. Frezatti $(2005$, p. 23) enfatiza que o Beyond Budgeting é uma tentativa de recuperar os aspectos qualitativos clássicos do orçamento, que se fossem cumpridos, não precisariam de um novo rótulo para ser administrativamente efetivos.

Peleias et al. (2012) apontam a existência de falhas no uso do orçamento tradicional e para os gestores as evidencias de comportamentos indesejados são suficientes para motivar a adoção de um novo modelo de gestão. Desta forma, após apresentar esta seção do referencial teórico, na sequência apresentam-se os procedimentos metodológicos.

\section{PROCEDIMENTOS METODOLÓGICOS}

\section{Tipo de pesquisa}

A abordagem deste estudo é qualitativa, que segundo Marconi e Lakatos (2010) interpreta e explora questões mais profundas, expondo a complexidade do comportamento e geralmente investiga hábitos, tendências e atitudes. A qualitativa se justifica pelo levantamento de dados através de entrevistas, com o objetivo de analisar e descrever os desafios, vantagens e críticas na análise da viabilidade de proposta de implementação do orçamento Beyond Budgeting. 
O procedimento técnico compreende um estudo de caso, que caracteriza-se, pelo estudo concentrado em um único caso (BEUREN, 2006). Além disso, também caracteriza-se como uma pesquisa documental primária e entrevista semiestruturada. Na pesquisa documental primária utilizou-se relatórios gerenciais fornecidos pelos proprietários da indústria que reuniram informações referentes aos controles orçamentários tradicionais existentes.

A pesquisa quanto aos fins é descritiva, que descreve características de determinada população, fenômeno ou estabelecimento de relação entre variáveis (GIL,2010). Nesta etapa foram descritas e analisadas as principais características da implementação do orçamento Beyond Budgeting, seus desafios, vantagens e críticas.

\section{Unidade de análise, coleta e análise dos dados}

A unidade de análise deste estudo é uma indústria, denominada de Industria A, em função do sigilo das informações de cunho estratégico, sua localização é no Brasil e comercializa seus produtos no mercado interno e externo. A escolha da Industria A justifica-se pela iniciativa dos próprios proprietários em implementar o orçamento Beyond Budgeting, ou seja, este estudo não é uma simples proposta, mas uma real implementação na empresa.

A coleta das informações e dados ocorreu por meio dos relatórios gerenciais, fornecidos pelo setor financeiro e setor contábil da Industria A, dentre os quais, cita-se como principais: relatório de contas a pagar; relatório de contas a receber; relatório de pagamentos efetuados; relatório de recebimentos realizados; relatórios de inadimplência; relatório de fluxo de caixa; relatório de compras; relatório de estoques; relatório de custos; relatório de vendas; além de demonstrações contábeis como Balancetes Contábeis anteriores, que demonstraram as características da organização. Os relatórios foram fornecidos pela empresa no período de Janeiro/2019 à Abril/2019.

As entrevistas foram realizadas diretamente com os dois proprietários da Industria A, nos dias 03 de abril de 2019 e 25 de abril de 2019. Na entrevista do dia 25 de abril foi apresentado aos proprietários uma análise prévia com as possibilidades para implementação do orçamento Beyond Budgeting, elaboradas a partir da análise de viabilidade para implementação do novo modelo orçamentário, onde foi discutido as possíveis modificações, bem como vantagens e desvantagens para futura implementação.

A entrevista semiestruturada, realizada com os proprietários, ocorreu com o auxílio do seguinte roteiro: a) Apresentação e caracterização da empresa: localização, histórico e estrutura administrativa, processo de gestão e planejamento estratégico; e a b) Análise da viabilidade de proposta de implementação do orçamento Beyond Budgeting na empresa, quanto aos aspectos essenciais necessários para utilização da ferramenta em substituição ao orçamento atualmente utilizado. 


\section{RESUTADOS E ANÁLISES}

\section{Processo de descentralização e desempenho do Beyond Budgeting}

A análise da implementação do orçamento Beyond Budgeting teve como base o estudo empírico, que demonstra como a Industria A deve elaborar seu processo de descentralização e desempenho, passando de um ambiente onde as decisões são centralizadas nos gestores (proprietários), para um ambiente de delegação e autonomia, com as tomada de decisões flexível.

Os proprietários da Industria A, entendem que a tomada de decisão de fato é centralizada, ou seja, tomam as principais decisões, delegando aos demais cargos uma autonomia parcial, sendo a alçada com uma decisão limitada. Este fato pode ser exemplificado com o processo de compras de matéria-prima, onde o comprador não pode efetuar a ordem de compra sem a aprovação do proprietário, independentemente do valor de aquisição, cabendo a alçada de comprador somente as compras de materiais auxiliares de menor relevância.

Outro exemplo para elucidar a centralização de decisão está no setor comercial, pois os representantes comerciais não tem autonomia para reduzir preços da tabela de vendas, cabendo exclusivamente aos proprietários, a autonomia para conceder descontos. Estes procedimentos acabam engessando a operacionalização do negócio e dificultam a agilidade no cotidiano da Industria A, pois as decisões não são compartilhadas.

A Industria A não possui medidas de controle para medir o desempenho, ou seja, não existe um programa para envolvimento de todos os colaboradores com o objetivo de atingir o melhor resultado, cabendo individualmente a cada funcionário a execução de suas atribuições, previamente delegadas. Neste sentido, as descentralizações foram sugeridas em conjunto com os proprietários da indústria A e que podem ser verificadas no Quadro 4.

Quadro 4 - O processo de descentralização e desempenho na Industria A com base no Beyond Budgeting

\section{Delegar decisão à autoridade}

Redefinir a autoridade, permitir que o nível hierárquico tenha seu poder de decisão, descentralizando- as. Tornar as pessoas aptas a tomar decisões, fornecendo cursos de liderança e gestão de equipes, bem como a qualificação necessária para melhor atender as necessidades da indústria.

Exemplo: Criar políticas de capacitação por cargos, definindo as competências necessárias para o melhor desempenho de cada função. Criar manual de procedimentos contemplando uma adequada segregação de funções.

Alterar o processo de aprovações de despesas de capital/projetos 
Criar novos métodos e relatórios padronizados extraídos do sistema de gestão da empresa, que possibilitem a melhor análise dos processos para aprovação de gastos e projetos de forma geral, definindo inclusive os valores gastos.

Exemplo: As compras de matérias primas devem ser realizadas mediante Ordem de Compra, devidamente autorizadas pelo Gestor Responsável do setor de compras, que terá um orçamento pré-definido para as compras.

\section{Criar/fortalecer estrutura de governança}

Implementação de estruturas de governança, possibilitando controles mais confiáveis para uma gestão descentralizadă.

Exemplo: Criar um manual de boas práticas de governança corporativa que possa servir para nortear os gestores.

Criar um Comitê de Governança Corporativa, inclusive com um Conselheiro externo, que possa agregar uma visão de fora da empresa, com conceitos de inovação empresarial.

\section{Reorganizar}

Adequar a estrutura da empresa, reestruturando o atual modelo de cargos e possibilitar treinamentos para novas funções.

Exemplo: Criação de planos de cargos e salários, fazendo um descritivo adequado para cada função e um plano de remuneração baseado em pré-requisitos que os cargos devem possuir para reajustes salariais. Criar um plano de carreira que possa gerar a expectativa dos funcionários para crescimento profissional.

\section{Atendimentos de clientes}

Dentro do sistema de TI, implementar procedimentos adequados para acompanhamento das vendas e pós-vendas, assim como mecanismos de monitoramento dos representantes comerciais.

Exemplo: Adotar como procedimento realizar pesquisas de satisfação dos clientes. Criar como o hábito controlar as vendas diariamente, através de ferramenta que possibilite mensurar os resultados das vendas, ou seja, produtos com maior volume de vendas, produtos mais lucrativos e, assim verificar quais produtos agregam maior margem de contribuição.

\section{Criar mercado interno}

A empresa deve posicionar-se de forma competitiva no mercado interno, adequando seus custos de forma que consiga competir de forma igualitária com os concorrentes.

Exemplo: Realizar pesquisas de mercado com frequência, pois é necessário um monitoramento da concorrência para acompanhar se os custos internos estão adequados com o mercado. Revisar os processos internos de produção.

\section{Configurar acordos de nível de serviço}

Formalizar a relação da empresa com terceiros, através de contratos ou termos de acordos comerciais, onde os mesmos devem demonstrar as condições contratuais do contratante e contratado.

Exemplo: Pactuar contratos com todos os terceiros para que se tenha uma formalização das relações de trabalho.

\section{Criar um processo para assimilar novas aquisições}

Revisar o custo de aquisição da matéria prima e materiais auxiliares, mensalmente, com o intuito de averiguar se o custo de produção está adequado.

Exemplo: Adotar como procedimento a cotação das principais matérias primas

e materiais auxiliares que formam o custo dos produtos com pelo menos três fornecedores.

Fonte: Elaborado pelos autores. 
O Quadro 4 aponta algumas medidas para descentralizar o nível hierárquico, criar políticas de governança corporativa, com uma adequada segregação de funções, que possibilite agilidade na tomada de decisão e um sistema de controle interno confiável para subsidiar informações. Neste sentido, serão promovidos programas de capacitação dos funcionários, como treinamentos de gestão e liderança, crédito e cobrança, contabilidade, fiscal e gestão de pessoas.

No atendimento das mudanças propostas no novo modelo de orçamento indica-se para referida Indústria a migração ou customização do software de gestão atual, buscando um Sistema de Gestão que permita uma melhor flexibilidade e agilidade, gerando informações confiáveis de forma integrada, permitindo um melhor gerenciamento de custos e processos de produção, principalmente no que refere-se a controles de estoque.

Em relação ao controle de desempenho, sugere-se a adoção de medidas que envolvam todos os colaboradores, gerando um ambiente integrado, onde todos estejam engajados, com o objetivo de atingir o melhor resultado. Para isso pretende-se investir em capacitação do setor de recursos humanos, que será o setor responsável para promover a integração entre todos.

No que refere-se ao alinhamento dos controles existentes ao modelo Beyond Budgeting, busca-se otimizar os controles orçamentários, possibilitando uma adequada interação e cruzamento de informações, de forma automatizada, contribuindo para uma análise eficaz do orçamento e do processo de gestão.

Os proprietários da Industria A, após análise das mudanças, acreditam que poderão gradativamente se adequar ao novo modelo de orçamento Beyond Budgeting, e consequentemente aprimorar o processo de gestão atual, que ainda é baseado nas estratégias adotadas pelos proprietários. Além disso, como a gestão está em fase de sucessão, os mesmos acreditam que a transição facilitará as mudanças, tendo em vista a necessidade de profissionalização da gestão.

\section{Processo adaptativo e de gestão do Beyond Budgeting}

A Indústria A não possui um planejamento estratégico e operacional formalizado, com a definição clara das políticas que estabelecem os rumos da organização, o que dificulta a tomada de decisão dos gestores.

No monitoramento do processo de gestão e do orçamento, a empresa não possui responsáveis específicos para monitorar se o planejamento realizado está de acordo com o previsto e, assim, fazer as devidas correções de direção, sempre que necessárias para alinhar aos objetivos da empresa. Tendo como base as análises discutidas com os proprietários da Industria A, apresenta-se no Quadro 5, possíveis adequações no processo adaptativo e de gestão, que possam gerar melhorias no planejamento orçamentário. 


\section{Rever as ações e processos de planejamento}

Rever o sistema de planejamento de ações, pois no modelo Beyond Budgeting o planejamento é contínuo e os recursos são liberados conforme a necessidade. Deve-se também reduzir burocracias, fazendo com que os colaboradores tenham autonomia de tomar decisões e implementar novos processos de controle. Implementar sistemáticas que permitam a antecipação de cenários, com o intuito de rever o planejamento e realizar os devidos ajustes, sempre que necessário.

Exemplo: Os sócios e gestores devem realizar reuniões periódicas para discutir os resultados realizados e assim antecipar-se as possíveis intempéries do mercado. Implementar o fluxo de caixa como ferramenta de controle financeiro.

Rever processos de formação de estratégias e indicadores

Ajustar e implementar o planejamento estratégico com premissas alinhadas aos níveis de gestão da empresa. Criar um ambiente de inovação, que traga melhorias. Definir a estratégia e acompanhar sua evolução, de modo que se consiga identificar seus pontos críticos e obter as informações necessárias para melhorar o processo de gestão.

Exemplo: Criação de comitê reunindo os principais gestores e líderes, para tratar sobre as premissas do planejamento estratégico da empresa a curto, médio e longo prazo. O planejamento deve consistir em avaliar as bases para o orçamento da empresa, passando pela avaliação do plano de vendas, custos e despesas alinhado com os objetivos de resultado almejados. Criação de indicadores para medir o desempenho da gestão, focados em resultado.

\section{Desmantelar contratos de desempenho fixo}

A empresa deve substituir os relatórios gerenciais usados atualmente para avaliação de desempenho dos setores, pois estes são fundamentados em métricas engessadas extraídas do sistema de gestão atual, que não atendem plenamente as necessidades dos gestores.

Exemplo: Criar procedimentos para avaliação de desempenho, que possam mensurar os resultados da empresa, através da customização do sistema de gestão atualmente utilizado, de acordo com as necessidades exigidas pela empresa.

\section{Rever o sistema de avaliação e recompensas}

A empresa deve criar uma cultura de desafio, onde os colaboradores devem ser desafiados a buscar o melhor desempenho de forma continua. Esta cultura pode ser implementada em todos os setores, com metas individualizadas e coletivas onde as recompensas podem ser condicionadas ao atingimento global.

Exemplo: Adaptação do modelo de comissionamento dos representantes comerciais, adequando o recebimento ao atingimento de metas flexíveis. Criação de uma política de recompensa adicional ao setor financeiro a partir da redução da inadimplência. Criação de uma bonificação extra para o setor de compras, caso consiga reduzir custos de insumos. Elaboração de um plano de remuneração baseado em distribuição de lucros. Neste sentido, todos ficam comprometidos com o resultado da empresa, pois serão recompensados.

Gerenciamento de Projetos 
A empresa deve organizar internamente, equipes que fiquem responsáveis pela execução dos projetos, cujo objetivo será fornecer subsídios que auxiliem na elaboração de orçamentos. A avaliação destes projetos deve ser realizada periodicamente para mensurar o progresso dos mesmos, assim como benefícios e riscos envolvidos.

Exemplo: Realização de reuniões quinzenais com as equipes para fazer avaliação dos projetos. As reuniões podem ser realizadas separadamente por equipes, sendo estas divididas por áreas, onde serão discutidos principalmente se a realização das tarefas está de acordo com o previsto e assim executando possíveis correções de rumo empresarial.

\section{Comunicar sobre o novo modelo}

A empresa deve criar políticas de comunicação interna para divulgar as premissas do projeto, bem como para explicar de forma clara e objetiva como serão executados os passos para implementação do orçamento Beyond Budgeting.

Exemplo: Realizar feedbacks periódicos sobre o andamento dos projetos e assim testar a clareza das explicações fornecidas e verificar a necessidade de aprimoramento e desempenho do orçamento.

\section{Obter garantia}

A empresa deve adotar procedimentos para avaliação do projeto de implementação do orçamento de forma que se tenha um monitoramento para garantira eficácia do resultado.

Exemplo: Criação de um Comitê interno de auditoria, de forma que se possa avaliar o andamento, e corrigir eventuais falhas que comprometam o sucesso da implementação do orçamento.

\section{Redesenhar produtos e formação de custos}

A empresa deve aprimorar o setor de pesquisa e desenvolvimento de produtos para estar alinhada com a demanda do mercado. Identificar os custos e a rentabilidade gerada de forma individualizada, com foco na rentabilidade.

Exemplo: Realização de pesquisas de mercado para identificar as necessidades do público alvo. Participação em feiras e eventos que possibilitem agregar as inovações do mercado. Adequar o sistema para gerar relatórios individualizados que demonstrem os custos por produto, bem como as suas respectivas rentabilidades.

\section{Redesenhar pacotes de gestão de informação}

Implementar ferramentas de gestão comercial com o objetivo de melhorar o atendimento aos clientes. Otimizar os relatórios gerenciais existentes, de forma que estes atendam de forma plena os gestores, e consequentemente auxiliem de forma eficaz na tomada de decisão.

Exemplo: Utilização de relatórios padronizados extraídos do sistema de gestão da empresa, ao invés de utilizar planilhas auxiliares em paralelo.

Fonte: Elaborado pelos autores.

Os proprietários da Industria A compreendem que o processo de mudança é árduo e o apoio dos sócios é fundamental para o sucesso da implementação. Dentro das adaptações sugeridas faz-se necessário a modificação dos contratos de desempenho fixo já pactuados, em especial, com 
os representantes comerciais, conforme proposto, além da criação de um plano de remuneração variável, baseado em um sistema de meritocracia.

A formalização do planejamento estratégico e operacional da indústria é essencial, que norteie a gestão do negócio, em curto, médio e longo prazo. Na obtenção disto é importante adotar políticas claras, que devem ser seguidas a fim de se atingir os objetivos da organização, além da implementação de novos processos de controle flexíveis, adaptáveis a necessidade do negócio, que permitam um monitoramento do desempenho de forma eficiente. Tais adequações passam pela substituição do sistema de gestão atualmente utilizado pela empresa.

Como complemento às mudanças propostas, será necessário a organização de comitês de gestão, para acompanhar a execução do planejamento realizado e monitorar periodicamente o andamento do processo de gestão para fazer as devidas correções de rumo para alcançar o resultado almejado.

As tarefas gerais e de gestão de projetos são fundamentais para que se atinja os objetivos do orçamento, as quais referem-se a melhorias internas de controles, principalmente no que se refere a mecanismo de monitoramento para prevenção de riscos que podem comprometer os resultados do negócio e também para manter a empresa alinhada de forma continua ao novo modelo de orçamento.

A administração da empresa avalia a gestão de projetos, como sendo de relevância, no contexto de implementação do planejamento orçamentário, uma vez que o objetivo principal está baseado no gerenciamento dos projetos, que tem como premissa fornecer subsídios para elaboração do orçamento.

Com estes ajustes os sócios/gestores concordam que a Industria A terá um padrão de organização, com planejamento consistente, alinhado com as suas estratégias e, portanto estará adequada ao novo modelo de orçamento, com gestão flexível, contribuindo para melhoria da eficiência operacional, o que garantirá o sucesso da implementação do orçamento Beyond Budgeting.

\section{Discussões sobre a implementação da Beyond Budgeting}

As principais dificuldades referem-se a centralização da gestão, pois não há uma adequada delegação e autoridade entres os cargos, comprometendo a autonomia dos envolvidos. Além disso, na Industria A não há uma adequada formalização de controles e procedimentos relacionados a governança corporativa e segregação de funções, além de não possuir políticas de planejamento estratégico e operacional claramente definidas (QUADRO 6). Constatou-se que o sistema de gestão utilizado pela empresa compromete a eficiência do processo operacional, pois não disponibiliza informações consolidadas para facilitar a tomada de decisão. 
Quadro 6 - Dificuldades e facilidades na implementação do Beyond Budgeting

\begin{tabular}{|c|c|c|}
\hline $\begin{array}{c}\text { PONTOS DE } \\
\text { ANÁLISE }\end{array}$ & DIFICULDADES & FACILIDADES \\
\hline $\begin{array}{l}\text { Delegação e } \\
\text { Autoridade }\end{array}$ & $\begin{array}{l}\text { A tomada de decisão é } \\
\text { centralizada, sendo assim, } \\
\text { não pode-se identificar a } \\
\text { autonomia de cada cargo. }\end{array}$ & $\begin{array}{l}\text { A possibilidade de descentralizar a } \\
\text { gestão e consequentemente flexibilizar a } \\
\text { tomada de decisão. }\end{array}$ \\
\hline $\begin{array}{l}\text { Governança } \\
\text { Corporativa }\end{array}$ & $\begin{array}{l}\text { Não possui políticas de } \\
\text { governança claramente } \\
\text { estabelecidas. }\end{array}$ & $\begin{array}{l}\text { As decisões estão centralizadas nos } \\
\text { proprietários, sem a formalização de } \\
\text { políticas de governança, porém os } \\
\text { sócios estão dispostos a criar boas } \\
\text { práticas de governança corporativa. }\end{array}$ \\
\hline $\begin{array}{l}\text { Segregação de } \\
\text { Funções }\end{array}$ & $\begin{array}{l}\text { A empresa possui } \\
\text { segregação de funções, } \\
\text { porém a mesma não } \\
\text { permite autonomia aos } \\
\text { cargos. }\end{array}$ & $\begin{array}{l}\text { Não há uma adequada segregação } \\
\text { de funções, mas pode-se estabelecer } \\
\text { a formalização de acordo com as } \\
\text { necessidades da empresa, atribuindo } \\
\text { a cada cargo suas devidas funções na } \\
\text { hierarquia. }\end{array}$ \\
\hline $\begin{array}{l}\text { Formalização } \\
\text { de Controles } \\
\text { Internos }\end{array}$ & $\begin{array}{l}\text { Não possui controles } \\
\text { formalizados. }\end{array}$ & $\begin{array}{l}\text { Pode-se implementar os controles } \\
\text { internos de forma a atender as } \\
\text { necessidades da empresa, garantindo a } \\
\text { confiabilidade das informações. }\end{array}$ \\
\hline $\begin{array}{l}\text { Atendimento } \\
\text { de clientes }\end{array}$ & $\begin{array}{l}\text { A empresa já possui } \\
\text { políticas de atendimento, } \\
\text { porém não são } \\
\text { satisfatórias. }\end{array}$ & $\begin{array}{l}\text { A empresa tem interesse em aprimorar } \\
\text { as políticas de atendimento, pois } \\
\text { prioriza a satisfação dos clientes. }\end{array}$ \\
\hline $\begin{array}{l}\text { Formalização } \\
\text { de Contratos } \\
\text { com terceiros }\end{array}$ & $\begin{array}{l}\text { A empresa não possui } \\
\text { política de formalização } \\
\text { para todos os contratos } \\
\text { com terceirizados. }\end{array}$ & $\begin{array}{l}\text { A empresa possui um bom } \\
\text { relacionamento com os Terceiros, } \\
\text { permitindo pactuar estes contratos de } \\
\text { forma retroativa. }\end{array}$ \\
\hline $\begin{array}{l}\text { Planejamento } \\
\text { Estratégico }\end{array}$ & $\begin{array}{l}\text { Não possui planejamento } \\
\text { estratégico consistente. }\end{array}$ & $\begin{array}{l}\text { Possibilidade de formalizar e } \\
\text { implementar o planejamento estratégico } \\
\text { de acordo com crenças e valores a serem } \\
\text { definidos pela empresa. }\end{array}$ \\
\hline $\begin{array}{l}\text { Planejamento } \\
\text { Operacional }\end{array}$ & $\begin{array}{l}\text { A empresa possui } \\
\text { controles para execução } \\
\text { das operações, porém não } \\
\text { está formalizado. }\end{array}$ & $\begin{array}{l}\text { Os controles não estão completamente } \\
\text { formalizados, mas tem-se uma base de } \\
\text { análise, de fácil acesso para iniciar as } \\
\text { melhorias propostas. }\end{array}$ \\
\hline $\begin{array}{c}\text { Plano de } \\
\text { Recompensas }\end{array}$ & $\begin{array}{l}\text { A empresa não possui um } \\
\text { plano de remuneração } \\
\text { variável. }\end{array}$ & $\begin{array}{l}\text { Os proprietários entendem que deve ser } \\
\text { formatado um plano de remuneração } \\
\text { baseado em meritocracia. }\end{array}$ \\
\hline Gestão Custos & $\begin{array}{l}\text { A empresa não possui } \\
\text { um controle de custos por } \\
\text { produto. }\end{array}$ & $\begin{array}{l}\text { Os proprietários concordam que deve } \\
\text { haver um controle efetivo dos custos, } \\
\text { onde se possa atribuir os custos de } \\
\text { produção diretos de cada produto e } \\
\text { assim averiguar a real rentabilidade. }\end{array}$ \\
\hline
\end{tabular}




\begin{tabular}{|c|l|l|}
\hline $\begin{array}{c}\text { PONTOS DE } \\
\text { ANÁLISE }\end{array}$ & \multicolumn{1}{|c|}{ DIFICULDADES } & \multicolumn{1}{c|}{ FACILIDADES } \\
\hline $\begin{array}{c}\text { Gestão de } \\
\text { Projetos }\end{array}$ & $\begin{array}{l}\text { A empresa não possui } \\
\text { equipes engajadas para } \\
\text { execução dos projetos. }\end{array}$ & $\begin{array}{l}\text { Os proprietários são flexíveis e tem } \\
\text { interesse em adequar as equipes } \\
\text { de acordo com a necessidade de } \\
\text { implementação. }\end{array}$ \\
\hline $\begin{array}{c}\text { Gestão da } \\
\text { Informação }\end{array}$ & $\begin{array}{l}\text { O Sistema de Gestão da } \\
\text { empresa não fornece todas } \\
\text { as informações necessárias } \\
\text { para devidas análise e } \\
\text { adequada tomada de } \\
\text { decisão. }\end{array}$ & $\begin{array}{l}\text { O software de Gestão utilizado } \\
\text { atualmente permite customizações, } \\
\text { desde que haja investimento da } \\
\text { empresa. Inclusive os sócios estão } \\
\text { dispostos a migrar para um novo } \\
\text { Software, com gestão mais flexível. }\end{array}$ \\
\hline
\end{tabular}

Fonte: Elaborado pelos autores.

Em relação as facilidades encontradas para implementação do orçamento Beyond Budgeting, destaca-se a disponibilidade dos proprietários em aprimorar o modelo atualmente adotado, inclusive migrando o atual software de gestão utilizado para agilizar os processos operacionais. Neste sentido, os proprietários estão dispostos a flexibilizar o orçamento atual, modificando principalmente a forma de gestão centralizada, passando a adotar um modelo de descentralização e liderança onde a delegação e autoridade será primordial para a autonomia e flexibilidade da tomada de decisão.

\section{CONCLUSÃO}

$\mathrm{O}$ orçamento Beyond Budgeting estabelece um modelo de gestão alternativo, flexível, descentralizado e participativo, evidencia respostas rápidas aos problemas da organização, inovação contínua de processos e produtos, excelência operacional garantida por um desempenho sustentável e melhora nos resultados. Neste sentido, este estudo objetivou a análise dos desafios, vantagens e críticas na implementação do Beyond Budgeting.

Os principais resultados apontam que a Industria A possui um ambiente onde as decisões são centralizadas nos proprietários, sem delegação e autonomia, não há políticas de governança e adequada segregação de funções. Os proprietários entendem que a mudança do orçamento tradicional para o orçamento Beyond Budgeting, trará um ambiente organizado de descentralização e maior flexibilidade, com a implementação de novos processos de controle flexíveis, adaptáveis a necessidade do negócio, que possibilitem o monitoramento do desempenho de forma eficiente e proporcionem agilidade na tomada de decisão.

Os principais desafios na implementação relacionam-se a mudança cultural, que deverá ser realizada para adaptar o orçamento. Contudo espera-se que estas modificações resultem em vantagens financeiras, na medida em que se terá uma melhora no resultado, devido a otimização nos processos. Conclui- 
se, portanto que a Industria A possui adaptabilidade ao modelo de orçamento Beyond Budgeting e perceberem que sua visão auxilia na geração de resultados e na gestão dos recursos humanos.

\section{REFERÊNCIAS}

BARBOSA FILHO, F. Estudo de Caso de uma empresa Brasileira de grande porte do ramos de alimentos, para analisar sua tendência ao Modelo Beyond Budgeting. 2004. 280f. Dissertação (Mestrado em Controladoria e Contabilidade Estratégica) - Centro Universitário Álvares Penteado, São Paulo, 2004.

BARBOSA FILHO, F.; PARISI, C. Análise da aderência ao Modelo Beyond Budgeting Round Table: O caso Sadia S.A. Revista Universo Contábil, v. 2, n. 1, p. 26-42, 2006.

BBRT. Beyond Budgeting: Enabling the lean, adaptive and ethical enterprise. 2003. Disponível em:<http://www.bbrt.org>. Acesso em 14 ago. 2018.

BEUREN, I. M. Como elaborar trabalhos monográficos em contabilidade: teoria e prática. 3. ed. São Paulo: Atlas, 2006.

BROMAN, S. L. S.; PINTO, S. R. R. Percepções sobre as Rotinas de Orçamento [Budgeting] como Lócus para Estudos sobre as Rotinas Organizacionais: um ensaio teórico. In: CONGRESSO NACIONAL DE ADMINISTRAÇÃO E CONTABILIDADE ADCONT, 8., 19 a 21 out. 2017. Anais... Rio de Janeiro: AdCont, 2017. 12f.

FRASER, H.; PFLAEGING, N. Os 12 princípios do Beyond Budgeting: como organizações podem ir "além dos orçamentos", deixando para trás a gestão por comando e controle. São Paulo: BBRT White Paper, 2007.

FREZATTI, F. Beyond Budgeting: Inovação ou resgate de antigos conceitos do orçamento empresarial? RAE, v. 45, n. 2, p. 23-33, 2005.

GABRIEL, J. R. B. Beyond Budgeting: Uma alternativa viável ao orçamento? Análise da literatura estrangeira. In: CONGRESSO ANPCONT, 11., 3 a 6 jun. 2016. Anais... Belo Horizonte: ANPCont, 2016. $18 \mathrm{f}$.

GAMA, M. J. N.; NEGREIROS, M. C. V.; SOUZA, A. D. Orçamento empresarial: O Beyond Budgeting (BB) como ferramenta de gestão global da organização com ênfase nos aspectos financeiros. Revista Contabilidade, Ciência da Gestão Finanças, v. 5, n. 2, p. 66-84, 2018.

GIL, A. C. Como elaborar projetos de pesquisa. 4. ed. São Paulo: Atlas, 2010.

GIMENEZ, L. et al. Uma análise comparativa das propostas beyond budgeting e gestão econômica. In: CONGRESSO BRASILEIRO DE CUSTOS, 16., 3 a 5 nov. 2009. Anais... Fortaleza: CBC, 2009. $15 f$. 
HOPE, J.; FRASER, R. Beyond Budgeting: how managers can break free from the annual performance trap. Boston: Harvard Bussines Scholl Pressc, 2003.

JERÔNIMO, L. R. Beyond Budgeting - O orçamento empresarial tradicional deve ser eliminado? Orçamento Empresarial, São Paulo, 08 jan. 2018.

LOPES, A. M. M.; MARQUES, M. A. N. C.; PENHA, R. S. BEYOND BUDGETING: panorama e tendências nas publicações científicas no Brasil. Caderno de Administração, v. 26, n. 1, p. 115-131, 2018.

MARCONI, M. A.; LAKATOS, E. M. Fundamentos de metodologia científica. 7. ed. São Paulo: Atlas, 2010.

PELEIAS, I. R. et al. Beyond Budgeting: percepções e adaptabilidade ao varejo bancário: pesquisa junto aos gestores de um grande banco brasileiro. Revista de Negócios, Blumenau, v17, n. 1, p. 101 -121, 2012.

PFLAEGING, N. Liderando com metas flexíveis: Beyond Budgeting. Porto Alegre: Bookman, 2009.

QUEIRÓS, M. C. C. Beyond Budgeting versus Orçamentos. 2010. 44f. Dissertação (Masters Degree in Finance and Taxes) - Faculdade de Economia Universidade do Porto, Porto, 2010.

ROSENBURG, C. O fim do orçamento. Revista Exame, 2008. Disponível em: <https:/ / exame.abril.com.br/negocios/o-fim-do-orcamento-m0040530/>. Acesso em: 23 ago. 2018.

SOARES, O. J.; NEVES JÚNIOR, I. J. Beyond Budgeting: Como otimizar o processo de gestão sem orçamentos. 2003. 15f. Artigo - Universidade Católica de Brasília, Brasília, 2003.

TARANTO, F. C. Análise comparativa do planejamento orçamentário tradicional com o modelo Beyond Budgeting: um estudo exploratório. 2006. 183f. Dissertação (Mestrado Profissional em Administração) - Universidade Metodista de Piracicaba UNIMEP, Piracicaba, 2006.

VALENTE, M. V. Beyond Budgeting: uma proposta de implementação. 2016. 53f. Dissertação (Mestrado em Contabilidade e Controle de Gestão) - Faculdade de Economia Universidade do Porto, Porto, 2016. 